\title{
Chromosomal radiosensitivity of human immunodeficiency virus positive/negative cervical cancer patients in South Africa
}

\author{
OLIVIA HERD ${ }^{1,2}$, FLAVIA FRANCIES ${ }^{1,2}$, JEFFREY KOTZEN $^{3}$, TRUDY SMITH ${ }^{4}$, ZWIDE NXUMALO $^{4}$, \\ XANTHENE MULLER ${ }^{1}$, JACOBUS SLABBERT ${ }^{1}$, ANNE VRAL $^{5}$ and ANS BAEYENS ${ }^{1,2}$ \\ ${ }^{1}$ Department of Radiation Biophysics, NRF-iThemba LABS, Somerset West 7129; ${ }^{2}$ Department of Radiation Sciences, \\ University of Witwatersrand; Departments of ${ }^{3}$ Radiation Oncology and ${ }^{4}$ Obstetrics and Gynaecology, \\ Charlotte Maxeke Johannesburg Academic Hospital, Johannesburg 2193, South Africa; \\ ${ }^{5}$ Department of Basic Medical Sciences, Ghent University, Ghent B-9000, Belgium
}

Received November 3, 2014; Accepted July 28, 2015

DOI: $10.3892 / \mathrm{mmr} .2015 .4504$

\begin{abstract}
Cervical cancer is the second most common cancer amongst South African women and is the leading cause of cancer-associated mortality in this region. Several international studies on radiation-induced DNA damage in lymphocytes of cervical cancer patients have remained inconclusive. Despite the high incidence of cervical cancer in South Africa, and the extensive use of radiotherapy to treat it, the chromosomal radiosensitivity of South African cervical cancer patients has not been studied to date. Since a high number of these patients are human immunodeficiency virus (HIV)-positive, the effect of HIV infection on chromosomal radiosensitivity was also investigated. Blood samples from 35 cervical cancer patients (20 HIV-negative and $15 \mathrm{HIV}$-positive) and 20 healthy controls were exposed to X-rays at doses of $6 \mathrm{MV}$ of 2 and 4 Gy in vitro. Chromosomal radiosensitivity was assessed using the micronucleus (MN) assay. MN scores were obtained using the Metafer 4 platform, an automated microscopic system. Three scoring methods of the MNScore module of Metafer were applied and compared. Cervical cancer patients had higher MN values than healthy controls, with HIV-positive patients having the highest MN values. Differences between groups were significant when using a scoring method that corrects for false positive and false negative MN. The present study suggested increased chromosomal radiosensitivity in HIV-positive South African cervical cancer patients.
\end{abstract}

Correspondence to: Professor Anne Vral, Department of Basic Medical Sciences, Ghent University, Campus Heymans, University Hospital, Building 6B3, De Pintelaan 185, Ghent B-9000, Belgium E-mail: anne.vral@ugent.be

Dr Ans Baeyens, Department of Radiation Sciences, University of Witwatersrand, 7 York Road, Parktown, Johannesburg 2193, South Africa

E-mail: ansbaeyens@hotmail.com

Key words: cervical cancer, chromosomal radiosensitivity, micronucleus assay, human immunodeficiency virus

\section{Introduction}

Cervical cancer is the most common cancer type amongst women in Sub-Saharan Africa, with an age-standardized incidence rate of 34.8 per $10^{5}$ females (1). Cervical cancer is also the leading cause of cancer-associated mortality amongst women in this region, with 22.5 per $10^{5}$ women dying from the disease annually (1). It is well-established that infection with oncogenic Human Papilloma Viruses (HPV) is the main cause of cervical cancer $(2,3)$. The high incidence of cervical cancer in Africa is likely due to a combination of factors. These include lack of awareness of the disease and its causes, as well as challenges in implementing regular HPV Papanicolaou (Pap)-smear screenings and HPV vaccinations, which have only recently been introduced into the South African health care system (4-6). While a large number of women are infected with the HPV virus, not all of them develop cervical cancer (7). Heritability studies have shown that susceptibility to cervical cancer may be genetic (8) and recent studies have reported an association between cervical cancer and genes involved in DNA damage repair, including APE1, XRCC2, XRCC3, ERCC1, ERCC2, ERCC4 and ATM (9-12).

Enhanced chromosomal radiosensitivity is associated with defects in genes involved in DNA damage repair (13). A possible inherited basis for radiosensitivity was first indicated by studies on patients with rare genetic syndromes, including Ataxia Telangiectasia and Nijmegen breakage syndrome (13). These patients were shown to display chromosomal radiosensitivity not only by clinical observations, but also by in vitro assays (14). Patients with these syndromes have germline mutations in genes involved in DNA damage repair and also display predisposition to numerous cancer types. Their increased chromosomal radiosensitivity encouraged investigations demonstrating an enhanced in vitro chromosomal radiosensitivity in patients with various cancer types, including breast, head and neck and prostate cancer (15-18). Mutations in DNA repair genes not only lead to increased chromosomal radiosensitivity in these patients but may also predispose them to the development of cancer $(13,17,19,20)$. The chromosomal radiosensitivity of lymphocytes of cervical cancer patients has 
been investigated in vitro using a variety of cytogenetic assays, however, results have been inconclusive (21-24).

A well-established method to measure chromosomal radiosensitivity is the micronucleus ( $\mathrm{MN}$ ) assay, which quantifies residual chromosomal damage resulting from mis-or non-repaired double-strand breaks after exposure to radiation. This assay can be performed on lymphocytes, which are an attractive model for radiosensitivity studies, as they are easily obtainable through venepuncture. MN scoring in this assay can be automated with an MN scoring module of the Metafer 4 platform. The MNScore micronucleus software module allows automated screening of binucleate cells and the subsequent scoring of MN in these cells (25). In this system, various scoring methods can be utilized that involve varying degrees of visual validation of automated scoring to correct for false positive and false negative $\mathrm{MN}$ and reject unsuitable cells $(26,27)$. The benefits and challenges of using the MN assay with the Metafer 4 platform have been documented elsewhere (26-32).

A study performed by our group (33) has previously shown that individuals infected with human immunodeficiency virus (HIV) are more chromosomally radiosensitive than HIV-negative individuals. In South Africa, 5.7 million people are HIV-positive (34). HIV, HPV and cervical cancer are epidemiologically associated and in 1993, invasive cervical carcinoma was classified as an acquired immune deficiency syndrome-defining illness by the United States Centers for Disease Control and Prevention (35). Rates of HPV infection increase with decreasing CD4-cell count (36) and studies have shown that HPV infection still persists in a high proportion of patients receiving highly active anti-retroviral therapy (37). Due to the high rate of HIV in Africa and its association with cervical cancer, it is likely that a significant proportion of cervical cancer patients seeking treatment are HIV-positive.

The aim of the present study was to investigate the in vitro chromosomal radiosensitivity in South African cervical cancer patients by means of the MN assay using a case-control study design. Concurrently, various scoring methods were evaluated when using the MN assay with the Metafer 4 platform. Due to the high rate of HIV in South Africa and its association with cervical cancer, the effect of the HIV infection status on chromosomal radiosensitivity of patients was also assessed.

\section{Patients and methods}

Study population. Blood samples were obtained via venepuncture from a total of 35 cervical cancer patients (mean age, 46 years) and 20 healthy female controls (mean age, 41 years). Among the patients with cervical cancer, 15 were infected with HIV (mean age, 43 years) and 20 were HIV-negative (mean age, 49 years). Patients were recruited from the public Charlotte Maxeke Johannesburg Academic Hospital (CMJAH; Johannesburg, South Africa), where they underwent a curative hysterectomy or radiotherapy. Clinical information on the patients was obtained from questionnaires and hospital files. None of the patients had received any chemotherapy or radiotherapy prior to sample collection. The tumors of all patients were squamous cell carcinoma. The majority of the patients had late-stage disease, five had early-stage disease and the disease stage was unknown for one patient. The healthy controls were staff members at CMJAH. All blood donors provided written informed consent and the study was approved by the Human Research Ethics Committee of University of Witwatersrand (Johannesburg, South Africa; no. M110230).

Irradiation and micronucleus assay. Lymphocyte cultures were established by adding $0.5 \mathrm{ml}$ heparinized blood to $4.5 \mathrm{ml}$ RPMI-1640 medium (BioWhittaker, Walkersville, MD, USA) supplemented with $13 \%$ foetal bovine serum (Gibco-BRL, Invitrogen Life Technologies, Inc., New York, NY, USA) and antibiotics $(50 \mathrm{U} / \mathrm{ml}$ penicillin and $50 \mathrm{mg} / \mathrm{ml}$ streptomycin; Gibco-BRL) in tissue culture flasks $\left(25 \mathrm{~cm}^{2}\right)$. The medium was pre-warmed to $37^{\circ} \mathrm{C}$ and gassed ( $5 \% \mathrm{CO}_{2} / 95 \%$ air). The cells were exposed to irradiation at the Radiation Oncology Unit of CMJAH. Culture flasks were placed in a Phantom-water tank (PolyScience, Warrington, PA, USA) at room temperature and irradiated with X-rays using a $6 \mathrm{MV}$ photon beam from a medical linear accelerator (Siemens Healthcare, Erlangen, Germany). Culture flasks were placed $100 \mathrm{~cm}$ away from the radiation source with an angle of 90 degrees. The field size at the depth of the sample was $10 \times 10 \mathrm{~cm}$. Samples were irradiated with 2 Gray (Gy) and 4 Gy at a dose rate of $\sim 1.33 \mathrm{~Gy} / \mathrm{min}$. A 0 Gy dose was used for the sham-irradiated control. For each irradiation dose, two co-cultures were set up. Immediately after irradiation, the lymphocytes were stimulated with $100 \mu \mathrm{l}$ phytohaemagglutinin (1-mg/ml stock solution; Sigma-Aldrich, St Louis, MO, USA) and $23 \mathrm{~h}$ later, $20 \mu \mathrm{l}$ cytochalasin B (stock solution of $1.5 \mathrm{mg} / \mathrm{ml}$; Sigma-Aldrich) was added to block cytokinesis. Cells were harvested at $70 \mathrm{~h}$ after stimulation using a cold $\left(4^{\circ} \mathrm{C}\right)$ hypotonic shock with $7 \mathrm{ml} 0.075 \mathrm{M} \mathrm{KCl}$ (Merck, Darmstadt, Germany). This was followed by fixation in methanol/acetic acid/Ringer's solution $(0.9 \% \mathrm{NaCl})(4: 1: 5)$ (Merck) at $4^{\circ} \mathrm{C}$ overnight. Subsequently, cells were fixed another three times with methanol/acetic acid (4:1) (Merck). Cell suspensions were dropped onto coded slides and stored at $4{ }^{\circ} \mathrm{C}$ overnight. Slides were mounted with vectashield containing DAPI (Vector Laboratories, Brussels, Belgium) prior to automatized scanning using the Metafer 4 platform (MetaSystems, Altlussheim, Germany) (28,32).

Scoring. Microscopic analysis was performed with the Metafer 4 platform connected to a motorized Zeiss AxioImager M1 microscope (Zeiss, Gottingen, Germany). The MetaSystems MNScore software module identifies binucleated cells and displays them in an image gallery with the quantified MN count per cell $(28,32)$. The present study used the parameters of the classifier of Willems et al (32) with minor adjustments. The system allows for the use of three different scoring methods, involving varying degrees of visual validation of automated scores. The first is the 'fully-automated' scoring method, in which MN counts are obtained directly by the MNScore module (32). The second is a 'semi-automated' scoring method which has been discussed in other publications $(26,27,38)$. In the present study, this scoring method, which only corrects false positive MN, was referred to as semi-automated A. For additional validation, the present study introduced a third scoring method, referred to as semi-automated B. In this method, every binucleated (BN) cell (with and without MN) was observed in the image gallery and false negative MN were corrected, in addition to the false 
Table I. Spontaneous and radiation-induced chromosomal radiosensitivity values for controls $(n=20)$ and cervical cancer patients $(\mathrm{n}=35)$ determined by micronucleus assay and evaluated using three scoring methods.

\begin{tabular}{|c|c|c|c|c|c|c|c|c|c|}
\hline \multirow[b]{2}{*}{ Group } & \multicolumn{3}{|c|}{ Automated } & \multicolumn{3}{|c|}{ Semi-Automated A } & \multicolumn{3}{|c|}{ Semi-Automated B } \\
\hline & 0 Gy & 2 Gy & 4 Gy & 0 Gy & $2 \mathrm{~Gy}$ & 4 Gy & 0 Gy & 2 Gy & 4 Gy \\
\hline \multicolumn{10}{|c|}{ Controls } \\
\hline Mean & 56 & 125 & 323 & 10 & 115 & 317 & 13 & 155 & 454 \\
\hline SEM & 8 & 8 & 13 & 1 & 5 & 11 & 1 & 6 & 9 \\
\hline \multicolumn{10}{|l|}{ Patients } \\
\hline Mean & 66 & 144 & 320 & 12 & 124 & 327 & 14 & $179^{\mathrm{a}}$ & $506^{\mathrm{a}, \mathrm{b}}$ \\
\hline SEM & 7 & 9 & 14 & 1 & 4 & 10 & 1 & 5 & 12 \\
\hline
\end{tabular}

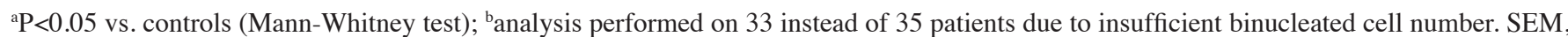
standard error of the mean.

positive MN corrected in semi-automated A. For each sample, 'fully-automated', 'semi-automated A' and 'semi-automated B' MN scores were determined by two experienced scorers. The average number of BN cells per data-point was 1,600. Datapoints (per patient/per irradiation dose) with $<500 \mathrm{BN}$ were not included. All results were normalized to the $\mathrm{MN}$ frequency in 1,000 BN cells.

Thenucleardivisionindex(NDI)wasalsocalculatedaccording to the following formula: $\mathrm{NDI}=(\mathrm{N} 1+2 \mathrm{~N} 2+3 \mathrm{~N} 3+4 \mathrm{~N} 4) / \mathrm{Ntotal}$, with N1-N4 being the number of cells with 1-4 nuclei and Ntotal the total number of cells scored (Ntotal $=500)$.

Statistical analysis. Statistical analysis was performed using Graphpad Prism 6 (GraphPad Inc., La Jolla, CA, USA). Differences between means of $\mathrm{MN}$ counts in the various groups were tested for significance with the Mann-Whitney U-test. This statistical test was used as it is a non-parametric, distribution-free test that is suitable for the comparison of groups with small sizes where no underlying distribution can be assumed. Values are expressed as the mean MN of a patient group/irradiation dose. $\mathrm{P}<0.05$ was considered to indicate a statistically significant difference between values.

\section{Results}

Establishment of an MN scoring method for assessing chromosomal radiosensitivity of cervical cancer patients vs. that of healthy controls. MN frequencies of cervical cancer patients were compared to those of healthy controls using the three different scoring methods of the Metafer 4 system. Radiation-induced MN yields were calculated by subtracting spontaneous MN yields from MN yields in irradiated cells. Spontaneous MN values and radiation-induced values for 2 Gy and 4 Gy are listed in Table I. Using the automated and 'semi-automated A' scoring method, no significant differences were detected between patients and controls. According of the results obtained with the 'semi-automated B' scoring method, patients with cervical cancer had clearly higher MN values compared to those of controls for all radiation doses tested; the difference between the groups was significant at $2 \mathrm{~Gy}$ $(\mathrm{P}=0.0075)$ and $4 \mathrm{~Gy}(\mathrm{P}=0.0059)$.
HIV-positive cervical cancer patients have increased chromosomal radiosensitivity compared with that of $H I V$-negative cervical cancer patients and healthy controls. To investigate whether the HIV status affects the chromosomal radiosensitivity of cervical cancer patients, the group of cervical cancer patients was divided into HIV-positive and HIV-negative patients. Based on the results shown in Table I, the 'semi-automated B' scoring method was used to compare HIV-positive and HIV-negative patients to controls. The MN values of healthy controls, HIV-positive patients and HIV-negative patients are presented in Fig. 1. The HIV-negative patients had clearly higher MN scores and therefore a higher chromosomal radiosensitivity compared to those of the controls; however, the difference was only significant at $4 \mathrm{~Gy}(\mathrm{P}=0.037)$. For $2 \mathrm{~Gy}$, there was no significant difference between HIV-negative cancer patients and controls $(\mathrm{P}=0.060)$, while there was a clear shift towards higher MN values in the patient group (Fig. 1).

In the HIV-positive patient group, two samples with insufficient BN measured at $4 \mathrm{~Gy}$ were excluded from the analysis. Although differences were not statistically significant, the HIV-positive patients had higher MN values than the HIV-negative patients. The HIV-positive patients had significantly higher radiation-induced $\mathrm{MN}$ values than the healthy controls at $2 \mathrm{~Gy}(\mathrm{P}=0.006)$ and $4 \mathrm{~Gy}(\mathrm{P}=0.008)$.

HIV-positive cervical cancer patients have lower NDIs than HIV-negative cervical cancer patients and healthy controls. To evaluate the quality of the MN assay in the groups of the present study, the nuclear division index was calculated. The healthy controls had NDIs of 2.170, 2.073 and 1.668 at 0,2 and $4 \mathrm{~Gy}$, respectively, while the cancer patients had NDIs of $2.117,1.883$ and 1.535 at these radiation doses, respectively. The differences in NDI were statistically significant between the two groups at 2 and 4 Gy ( $\mathrm{P}=0.0091$ and $\mathrm{P}=0.0182$, respectively). The HIV-positive cancer patients had the lowest NDIs among all groups. The NDIs for HIV-positive versus HIV-negative patients were 2,$074 ; 1,842 ; 1,529$ vs 2,$160 ; 1,928 ; 1,535$. The NDI of the HIV-positive group was lower than the other groups, but not significantly. 

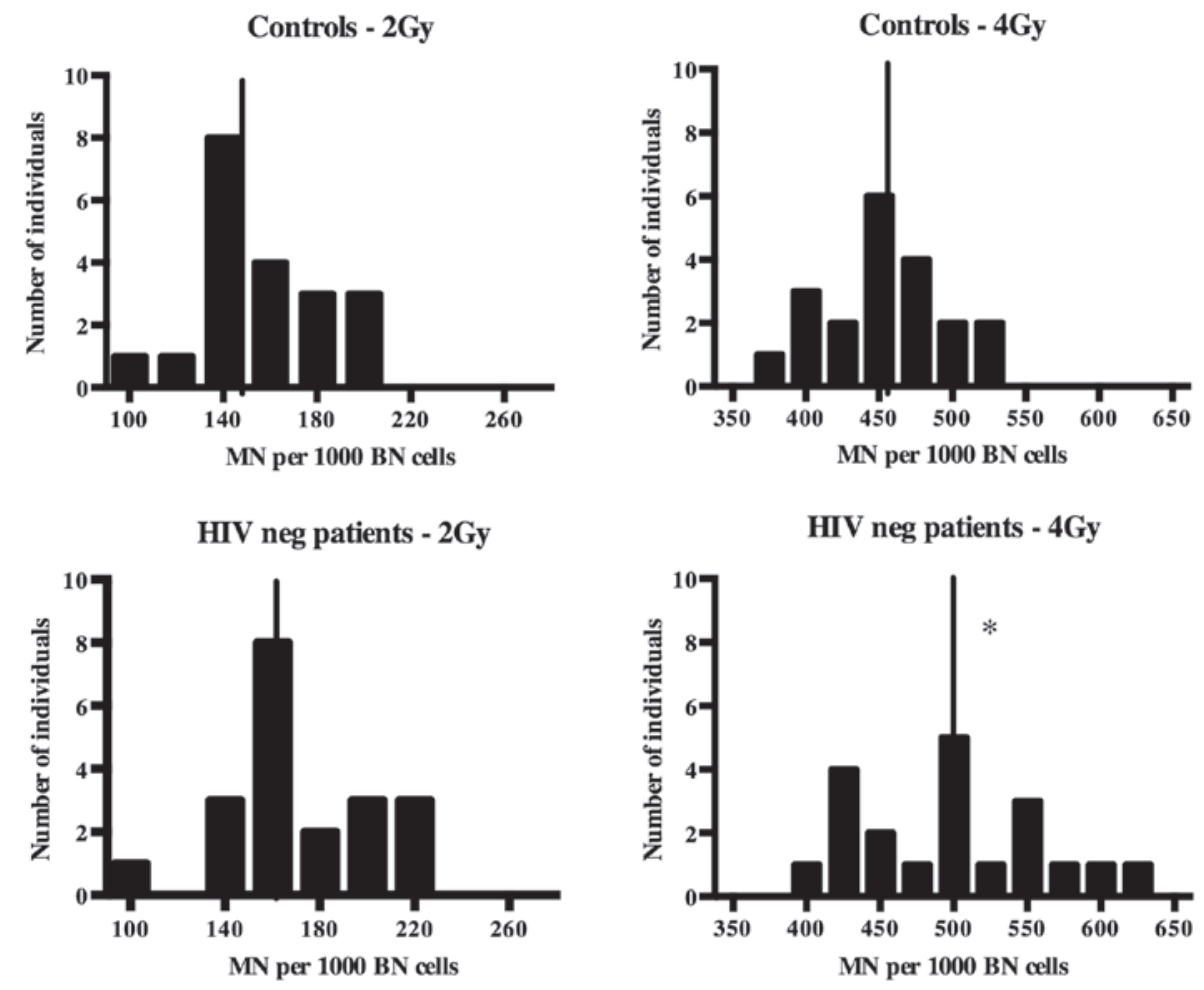

HIV pos patients - $2 \mathrm{~Gy}$
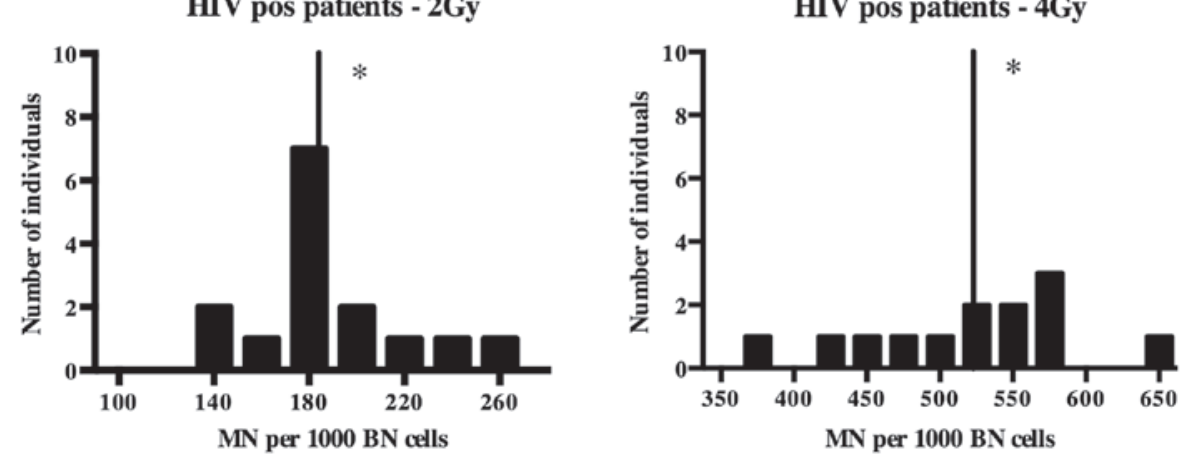

Figure 1. Radiation-induced MN yields after $2 \mathrm{~Gy}$ and $4 \mathrm{~Gy}$ irradiations for cancer patients and controls. Controls ( $\mathrm{n}=20)$; HIV-negative patients ( $\mathrm{n}=20$ ); HIV-positive patients $(n=15)$. Midlines indicate the mean MN yield of the group. " $\mathrm{P}<0.05$ vs. controls. HIV, human immunodeficiency virus; MN, micronucleus; pos, posivite; neg, negative; BN, binucleated.

\section{Discussion}

The aim of the present study was to compare the chromosomal radiosensitivity of South African cervical cancer patients with that of healthy controls using the MN assay. The development of the MNScore software module by MetaSystems has allowed for the automation of MN scoring (25). The system has been documented in several biodosimetric and cancer-associated studies and allows for the application of various scoring methods that involve varying degrees of visual validation of automated scores (26-32). The presence of apoptotic nuclei and a wide range in cell size have been mentioned as factors impairing the efficiency of the Metafer system $(26,29)$. Another challenge noted is that the system 'may fail to identify all MN if they are close or attached to the main nuclei or if there are more than one MN in the same BN cell' (29). The majority of the patient group in the present study had late-stage cervical cancer, which may have contributed to apoptosis and variation in cell size; furthermore, the doses of irradiation administered in vitro may have resulted in multiple MN. For these reasons, the present study included a 'semi-automated B' scoring method as an extra validation step to correct for false positive as well as false negative $\mathrm{MN}$ in all $\mathrm{BN}$ cells detected. While 'semi-automated B' scoring using the Metafer platform is more time-consuming than 'semi-automated A' scoring, it is more rapid than manual scoring under a microscope. Furthermore, the Metafer system has additional benefits, including the less subjective BN screening and the generation of a full image gallery, which can be archived as a 'virtual slide' that can be re-analyzed whenever necessary. The Metafer platform has been used in two similar population studies on breast and prostate cancer populations $(30,31)$. Using the automated scoring only, Varga et al $(30,31)$ were able to clearly distinguish between breast cancer patients and controls but not between prostate cancer patients and controls. To the best of our knowledge, Metafer scoring has not previously 
been used to investigate a cervical cancer population. In the present study, when cervical cancer patients were compared to controls using the 'fully-automated' and 'semi-automated A' method, no differences were observed between patients and controls. However, the 'semi-automated B' scoring method determined significantly higher $\mathrm{MN}$ values for the patient group as compared to those of the control group at 2 and $4 \mathrm{~Gy}$. At the $4 \mathrm{~Gy}$ dose, a significant percentage of BN had multiple MN, which was missed by the 'fully-automated' and 'semi-automated A' scoring methods. Another reason for the inaccuracy of the 'fully-automated' and 'semi-automated A' methods may have been the high level of cell debris that was noted on the slides of the cancer patients, which was a possible result of increased apoptosis due to elevated radiosensitivity or other types of cellular stress associated with late-stage disease. The lower yield of binucleated cells in the cancer group, which may have also been a result of apoptosis or cellular stress, was reflected by the significantly lower NDI compared to that in the healthy control group. All of these circumstances may have resulted in false positive MN that may have affected the automated scoring.

The results of the present study indicated an increased chromosomal radiosensitivity in patients with cervical cancer compared to that of controls. Previous studies on the chromosomal radiosensitivity of lymphocytes of cervical cancer patients have been inconclusive. In a study by Ban et al (22) using the MN assay, patients were found to have lower MN frequencies than controls. However, the blood samples of a large proportion of the patients were taken after or during radiotherapy treatment. This resulted in high spontaneous MN values, which affected the radiation-induced MN values. It was also suggested by the authors that the lower $\mathrm{MN}$ values determined in cervical cancer patients may be the result of an adaptive response of the patients to clinical therapy. Encheva et al (39), who performed a similar study to the present one, compared MN values of lymphocytes from 40 gynecological cancer patients ( 23 with cervical and 17 with endometrial cancer combined into one group) to those of 10 healthy control subjects. The lymphocytes from the combined gynecological cancer patients and the controls had similar MN values after exposure to a dose of $1.5 \mathrm{~Gy}$ in vitro. The inclusion of 17 patients with endometrial cancer makes it difficult to draw conclusions on the chromosomal radiosensitivity of cervical cancer patients alone. The present study was performed on a cohort of patients with cervical cancer, mainly at the late stage.

It is widely accepted that inherited genes have a role in cervical cancer susceptibility, as only a fraction of women with HPV infection develop cervical cancer, and the disease shows familial clustering (40). HPV-induced cervical carcinogenesis is a complex, multi-faceted process that has yet to be fully elucidated (7). While numerous studies on cervical cancer have focused on genes involved in the immune response (41-43), cervical cancer-associated genes involved in DNA damage repair are also an area of interest. Recent studies have shown associations with genes involved in DNA damage repair and a risk for cervical cancer $(9-12,44)$. In addition, studies have shown that Fanconi Anemia (FA) patients, who have deficient DNA damage repair mechanisms, are more susceptible to HPV-positive head and neck squamous cell carcinomas compared to non-FA patients with the same lesions (45). Park et al (46) reported an association between HPV and the FA pathway. Defects in DNA damage-response genes are known to affect chromosomal radiosensitivity (47). The increased chromosomal radiosensitivity observed in the present study suggested deficient DNA damage response signaling, which may have had a role in the genesis of cervical cancer. The exact role of DNA damage repair genes in the development and progression of cervical cancer remains to be fully elucidated. Evidence from a study using retroviruses showed that when a virus was integrated into the host's genome, a double-strand break (DSB) was formed, causing a DNA damage response similar to that observed when cells were exposed to ionizing radiation (48). If these DSB are not repaired and the integration process is not properly regulated, it can result in genomic instability, which can lead to carcinogenesis (12). It was also reported that the preferential targets of HPV integration are common fragile sites (49). DNA damage repair genes, including ATR, BRCA1, CHK1, have been shown to have a role in fragile site stability and expression (50-53). There may be a link between compromised DNA damage repair, fragile site stability and susceptibility to HPV integration and subsequent carcinogenesis.

A previous study by our group showed that HIV-positive individuals were more radiosensitive than non-infected individuals (33). HIV infection is common in Africa and the epidemiological link between HIV and cervical cancer implies that a large number of women seeking treatment (often radiotherapy) of the disease are HIV-positive. For this reason, the present study examined a group of HIV-positive cervical cancer patients as part of the study cohort. In two of the HIV-positive patients, the number of BN after the 4 Gy dose was too low for the evaluation of the MN score. This was likely due to HIV infection, which affects the CD4 count, in combination with the late-stage cervical cancer, causing cells to not withstand the cytotoxicity of a dose as high as $4 \mathrm{~Gy}$. HIV-positive cervical cancer patients had higher MN values than HIV-negative cervical cancer patients, despite the differences not being significant. This suggested that HIV infection enhanced the radiosensitivity of cervical cancer patients. The MN values of HIV-positive patients were significantly higher than those of the healthy controls at 2 Gy and 4 Gy. These results were consistent with those of Baeyens et al (33).

The present study showed that when using the Metafer system on cancer populations with advanced disease or HIV, the 'semi-automated B' scoring method yields the most reliable results. This technique may also be useful for the assessment of the radiosensitivity of population groups with other types of cancer. The results also showed that cervical cancer patients had higher MN values than those of the controls, suggesting increased chromosomal radiosensitivity. The findings of the present study confirmed that cervical cancer patients seeking radiotherapy who are HIV-positive may form a distinct group that requires individualized treatments. It may be useful to follow up the in vitro data with the clinical response of cervical cancer patients with HIV infection undergoing radiotherapy. Evidence suggested that these patients suffer from increased radiation-induced side-effects; however, further investigation is required to confirm this (54-56). From the results of the present study, it can be deduced that when performing studies 
in developing countries, factors such as the HIV status should be considered. Further studies are required to investigate the link between chromosomal radiosensitivity, DNA damage repair genes and the underlying mechanisms of susceptibility to HPV-induced carcinogenesis. Such studies may identify a marker for increased cervical cancer risk in women with HPV infection and may assist in the identification of individuals requiring regular pap-smears, which may reduce medical expenses in resource-limited countries such as South Africa.

\section{Acknowledgements}

The present study was supported by the iThemba Laboratory for Accelerated Based Science (LABS), Nuclear Technologies in Medicine and the Biosciences Initiative [NTeMBI; a national technology platform developed and managed by the South African Nuclear Energy Corporation (NECSA)], the 'Competitive Support for Unrated Researchers' grant (no. 78798) of the National Research Foundation, South Africa and the 'VLIR Own Initiative Programme' between Belgium and South Africa (no. ZEIN2011 pr387). The authors wish to thank all donors who participated in the present study.

\section{References}

1. IARC: International agency for research on cancer. GLOBOCAN report 2012.

2. Bosch FX, Lorincz A, Muñoz N, Meijer CJ and Shah KV: The causal relation between human papillomavirus and cervical cancer. J Clin Pathol 55: 244-265, 2002.

3. Walboomers JM, Jacobs MV, Manos MM, Bosch FX, Kummer JA, Shah KV, Snijders PJ, Peto J, Meijer CJ and Muñoz N: Human papillomavirus is a necessary cause of invasive cervical cancer worldwide. J Pathol 189: 12-19, 1999.

4. Anorlu RI: Cervical cancer: the sub-Saharan African perspective. Reprod Health Matters 16: 41-49, 2008.

5. Sitas F, Parkin DM, Chirenje M, Stein L, Abratt R and Wabinga H: Part II: Cancer in indigenous africans-causes and control. Lancet Oncol 9: 786-795, 2008.

6. DOHSA: South African department of health, 2014.

7. Woodman CB, Collins SI and Young LS: The natural history of cervical HPV infection: Unresolved issues. Nat Rev Cancer 7: 11-22, 2007.

8. Magnusson PK, Lichtenstein P and Gyllensten UB: Heritability of cervical tumours. Int J Cancer 88: 698-701, 2000.

9. Wang M, Chu H, Wang S, Wang M, Wang W, Han S and Zhang Z: Genetic variant in APE1 gene promoter contributes to cervical cancer risk. Am J Obstet Gynecol 209: 360 e1-7, 2013.

10. Pérez LO, Crivaro A, Barbisan G, Poleri L and Golijow CD: XRCC2 R188H (rs3218536), XRCC3 T241 M (rs861539) and R243H (rs77381814) single nucleotide polymorphisms in cervical cancer risk. Pathol Oncol Res 19: 553-558, 2013.

11. Bajpai D, Banerjee A, Pathak S, Jain SK and Singh N: Decreased expression of DNA repair genes (XRCC1, ERCC1, ERCC2 and ERCC4) in squamous intraepithelial lesion and invasive squamous cell carcinoma of the cervix. Mol Cell Biochem 377: 45-53, 2013.

12. Oliveira S, Ribeiro J, Sousa H, Pinto D, Baldaque I and Medeiros R: Genetic polymorphisms and cervical cancer development: ATM G5557A and p53bp1 C1236 G. Oncol Rep 27: 1188-1192, 2012.

13. Jeggo P and Lavin MF: Cellular radiosensitivity: How much better do we understand it? Int J Radiat Biol 85: 1061-1081, 2009.

14. Huo YK, Wang Z, Hong JH, Chessa L, McBride WH, Perlman SL and Gatti RA: Radiosensitivity of ataxia-telangiectasia, X-linked agammaglobulinemia and related syndromes using a modified colony survival assay. Cancer Res 54: 2544-2547, 1994.

15. Jones LA, Scott D, Cowan R and Roberts SA: Abnormal radiosensitivity of lymphocytes from breast cancer patients with excessive normal tissue damage after radiotherapy: chromosome aberrations after low dose-rate irradiation. Int J Radiat Biol 67: $519-528,1995$.
16. Parshad R, Sanford KK and Jones GM: Chromatid damage after G2 phase X-irradiation of cells from cancer-prone individuals implicates deficiency in DNA repair. Proc Natl Acad Sci USA 80: 5612-5616, 1983.

17. Baeyens A, Thierens H, Claes K, Poppe B, Messiaen L, De Ridder L and Vral A: Chromosomal radiosensitivity in breast cancer patients with a known or putative genetic predisposition. Br J Cancer 87: 1379-1385, 2002.

18. Riches AC, Bryant PE, Steel CM, Gleig A, Robertson AJ, Preece PE and Thompson AM: Chromosomal radiosensitivity in G2-phase lymphocytes identifies breast cancer patients with distinctive tumour characteristics. Br J Cancer 85: 1157-1161, 2001.

19. Terzoudi GI, Jung T, Hain J, Vrouvas J, Margaritis K, Donta-Bakoyianni C, Makropoulos V, Angelakis P and Pantelias GE: Increased G2 chromosomal radiosensitivity in cancer patients: The role of cdk1/cyclin-B activity level in the mechanisms involved. Int J Radiat Biol 76: 607-615, 2000.

20. Scott D, Spreadborough A, Levine E and Roberts SA: Genetic predisposition in breast cancer. Lancet 344: 1444, 1994.

21. Baria K, Warren C, Roberts SA, West CM and Scott D: Chromosomal radiosensitivity as a marker of predisposition to common cancers? Br J Cancer 84: 892-896, 2001.

22. Ban S, Konomi C, Iwakawa M, Yamada S, Ohno T, Tsuji H, Noda S, Matui Y, Harada Y, Cologne JB and Imai T: Radiosensitivity of peripheral blood lymphocytes obtained from patients with cancers of the breast, head and neck or cervix as determined with a micronucleus assay. J Radiat Res 45: 535-541, 2004.

23. Bozsakyová E, Wsólová L and Chalupa I: Spontaneous and gamma-ray-induced sister chromatid exchanges in patients with carcinoma of cervix uteri. Int J Radiat Biol 81: 177-185, 2005.

24. Gabelova A, Farkasova T, Gurska S, Machackova Z, Lukacko P and Witkovsky V: Radiosensitivity of peripheral blood lymphocytes from healthy donors and cervical cancer patients; the correspondence of in vitro data with the clinical outcome. Neoplasma 55: 182-191, 2008.

25. Schunck C, Johannes T, Varga D, Lörch T and Plesch A: New developments in automated cytogenetic imaging: Unattended scoring of dicentric chromosomes, micronuclei, single cell gel electrophoresis and fluorescence signals. Cytogenet Genome Res 104: 383-389, 2004.

26. Bolognesi C, Balia C, Roggieri P, et al: Micronucleus test for radiation biodosimetry in mass casualty events: Evaluation of visual and automated scoring. Radiation Measurements 46: 169-175, 2011.

27. Baeyens A, Swanson R, Herd O, Ainsbury E, Mabhengu T, Willem P, Thierens H, Slabbert JP and Vral A: A semi-automated micronucleus-centromere assay to assess low-dose radiation exposure in human lymphocytes. Int J Radiat Biol 87: 923-931, 2011.

28. Varga D, Johannes T, Jainta S, Schuster S, Schwarz-Boeger U, Kiechle M, Patino Garcia B and Vogel W: An automated scoring procedure for the micronucleus test by image analysis. Mutagenesis 19: 391-397, 2004.

29. Fenech M, Kirsch-Volders M, Rossnerova A, Sram R, Romm H, Bolognesi C, Ramakumar A, Soussaline F, Schunck C and Elhajouji A: HUMN project initiative and review of validation, quality control and prospects for further development of automated micronucleus assays using image cytometry systems. Int J Hyg Environ Health 216: 541-552, 2013.

30. Varga D, Michel I, Patino-Garcia B, Paiss T, Vogel W and Maier C: Radiosensitivity detected by the micronucleus test is not generally increased in sporadic prostate cancer patients. Cytogenet Genome Res 111: 41-45, 2005.

31. Varga D, Hoegel J, Maier C, Jainta S, Hoehne M, Patino-Garcia B, Michel I, Schwarz-Boeger U, Kiechle M, Kreienberg R and Vogel W: On the difference of micronucleus frequencies in peripheral blood lymphocytes between breast cancer patients and controls. Mutagenesis 21: 313-320, 2006.

32. Willems P, August L, Slabbert J, Romm H, Oestreicher U, Thierens $\mathrm{H}$ and Vral A: Automated micronucleus (MN) scoring for population triage in case of large scale radiation events. Int J Radiat Biol 86: 2-11, 2010.

33. Baeyens A, Slabbert JP, Willem P, Jozela S, Van Der Merwe D and Vral A: Chromosomal radiosensitivity of HIV positive individuals. Int J Radiat Biol 86: 584-592, 2010.

34. STATSSA: Statistics South Africa: Mid-year population estimates South Africa, 2013. 
35. CDC: Centre for disease control. Classification system for HIV infection and expanded surveillance case definition for AIDS among adolescents and adults, 1993.

36. Firnhaber C, Van Le H, Pettifor A, Schulze D, Michelow P, Sanne IM, Lewis DA, Williamson AL, Allan B, Williams S, et al: Association between cervical dysplasia and human papillomavirus in HIV seropositive women from Johannesburg South Africa. Cancer Causes Control 21: 433-443, 2010.

37. Heard I, Schmitz V, Costagliola D, Orth G and Kazatchkine MD: Early regression of cervical lesions in HIV-seropositive women receiving highly active antiretroviral therapy. AIDS 12: 1459-1464, 1998

38. Thierens H, Vral A, Vandevoorde C, Vandersickel V, de Gelder V, Romm H, Oestreicher U, Rothkamm K, Barnard S, Ainsbury E4, et al: Is a semi-automated approach indicated in the application of the automated micronucleus assay for triage purposes? Radiat Prot Dosimetry 159: 87-94, 2014.

39. Encheva E, Deleva S, Hristova R, Hadjidekova V and Hadjieva T: Investigating micronucleus assay applicability for prediction of normal tissue intrinsic radiosensitivity in gynecological cancer patients. Rep Pract Oncol Radiother 17: 24-31, 2011.

40. Magnusson PK, Sparén P and Gyllensten UB: Genetic link to cervical tumours. Nature 400: 29-30, 1999.

41. Chen D, Hammer J, Lindquist D, Idahl A and Gyllensten U: A variant upstream of HLA-DRB1 and multiple variants in MICA influence susceptibility to cervical cancer in a Swedish population. Cancer Med 3: 190-198, 2014.

42. Jiang J, Li N, Shen Y, Liu J, Liu L, Du J, Lei Y, Wen Y, Yang L, Guo L, et al: Genetic variants in HLA-DP/DQ contribute to risk of cervical cancer: A two-stage study in Chinese women. Gynecol Oncol 129: 401-405, 2013.

43. Chen D, Juko-Pecirep I, Hammer J, Ivansson E, Enroth S, Gustavsson I, Feuk L, Magnusson PK, McKay JD, Wilander E and Gyllensten U: Genome-wide association study of susceptibility loci for cervical cancer. J Natl Cancer Inst 105: 624-633, 2013.

44. Wang SS, Gonzalez P, Yu K, Porras C, Li Q, Safaeian M, Rodriguez AC, Sherman ME, Bratti C, Schiffman M, et al: Common genetic variants and risk for HPV persistence and progression to cervical cancer. PLoS One 5: e8667, 2010.
45. Kutler DI, Wreesmann VB, Goberdhan A, Ben-Porat L, Satagopan J, Ngai I, Huvos AG, Giampietro P, Levran O, Pujara K, et al: Human papillomavirus DNA and p53 polymorphisms in squamous cell carcinomas from Fanconi anemia patients. J Natl Cancer Inst 95: 1718-1721, 2003.

46. Park JW, Pitot HC, Strati K, Spardy N, Duensing S, Grompe M and Lambert PF: Deficiencies in the Fanconi anemia DNA damage response pathway increase sensitivity to HPV-associated head and neck cancer. Cancer Res 70: 9959-9968, 2010.

47. Iarmarcovai G, Bonassi S, Botta A, Baan RA and Orsière T: Genetic polymorphisms and micronucleus formation: a review of the literature. Mutat Res 658: 215-33, 2008.

48. Skalka AM and Katz RA: Retroviral DNA integration and the DNA damage response. Cell Death Differ 12 (Suppl 1): 971-978, 2005.

49. Thorland EC, Myers SL, Gostout BS and Smith DI: Common fragile sites are preferential targets for HPV16 integrations in cervical tumors. Oncogene 22: 1225-1237, 2003.

50. Casper AM, Nghiem P, Arlt MF and Glover TW: ATR regulates fragile site stability. Cell 111: 779-789, 2002.

51. Arlt MF, Xu B, Durkin SG, Casper AM, Kastan MB and Glover TW: BRCA1 is required for common-fragile-site stability via its G2/M checkpoint function. Mol Cell Biol 24: 6701-6709, 2004.

52. Durkin SG, Arlt MF, Howlett NG and Glover TW: Depletion of CHK1, but not CHK2, induces chromosomal instability and breaks at common fragile sites. Oncogene 25: 4381-4388, 2006.

53. Glover TW, Arlt MF, Casper AM and Durkin SG: Mechanisms of common fragile site instability. Hum Mol Genet 14 Spec No. 2: R197-R205, 2005.

54. Housri N, Yarchoan R and Kaushal A: Radiotherapy for patients with the human immunodeficiency virus: Are special precautions necessary? Cancer 116: 273-283, 2010.

55. Shrivastava SK, Engineer R, Rajadhyaksha S and Dinshaw KA: HIV infection and invasive cervical cancers, treatment with radiation therapy: Toxicity and outcome. Radiother Oncol 74: 31-35, 2005.

56. Gichangi P, Bwayo J, Estambale B, Rogo K, Njuguna E, Ojwang S and Temmerman M: HIV impact on acute morbidity and pelvic tumor control following radiotherapy for cervical cancer. Gynecol Oncol 100: 405-411, 2006. 